\title{
Increases in female academic productivity and female mentorship highlight sustained progress in previously identified neurosurgical gender disparities
}

\author{
Birra Taha, MD, ${ }^{1}$ Praneeth Sadda, MD, ${ }^{2}$ Graham Winston, MD, ${ }^{3}$ Eseosa Odigie, BS, ${ }^{3}$ \\ Cristina Londono, MD, ${ }^{4}$ Jeffrey P. Greenfield, MD, PhD, ${ }^{3}$ Susan C. Pannullo, MD, ${ }^{3}$ and \\ Caitlin Hoffman, MD ${ }^{3}$
}

${ }^{1}$ Department of Neurosurgery, University of Minnesota Medical Center, Minneapolis, Minnesota; ${ }^{2}$ Department of Medicine, Tulane University Medical Center, New Orleans, Louisiana; ${ }^{3}$ Department of Neurological Surgery, NewYork-Presbyterian Hospital, Weill Cornell Medical College; and "Weill Cornell Medical College, New York, New York

\begin{abstract}
OBJECTIVE A meta-analysis was performed to understand disparities in the representation of female authorship within the neurosurgical literature and implications for career advancement of women in neurosurgery.

METHODS Author names for articles published in 16 of the top neurosurgical journals from 2002 to 2019 were obtained from MEDLINE. The gender of each author was determined using automated prediction methods. Publication trends were compared over time and across subdisciplines. Female authorship was also compared to the proportionate composition of women in the field over time.
\end{abstract}

RESULTS The metadata obtained from 16 major neurosurgical journals yielded 66,546 research articles. Gender was successfully determined for $96 \%(127,809 / 133,578)$ of first and senior authors, while the remainder $(3.9 \%)$ were unable to be determined through prediction methods. Across all years, $13.3 \%$ (8826) of articles had female first authorship and $9.1 \%$ (6073) had female senior authorship. Female first authorship increased significantly over time from $5.8 \%$ in 2002 to $17.2 \%$ in 2019 ( $p$ < 0.001). Female senior authorship also increased significantly over time, from $5.5 \%$ in 2002 to $12.0 \%$ in 2019 ( $p<0.001)$. The journals with the highest proportions of female first authors and senior authors were the Journal of Neurosurgery: Pediatrics (33.5\%) and the Asian Journal of Neurosurgery (23.8\%), respectively. Operative Neurosurgery had the lowest fraction of female first (12.4\%) and senior (4.7\%) authors. There was a significant difference between the year-by-year proportion of female neurosurgical trainees and the year-by-year proportion of female neurosurgical first $(p<0.001)$ and senior $(p<0.001)$ authors. Articles were also more likely to have a female first author if the senior author of the article was female (OR 2.69, Cl 2.52-2.86; p<0.001). From 1944 to 2019, the Journal of Neurosurgery showed a steady increase in female first and senior authorship, with a plateau beginning in the 1990 s.

CONCLUSIONS Large meta-analysis techniques have the potential to effectively leverage large amounts of bibliometric data to quantify the representation of female authorship in the neurosurgical literature. The proportion of female authors in major neurosurgical journals has steadily increased. However, the rate of increase in female senior authorship has lagged behind the rate of increase in first authorship, indicating a disparity in academic advancement in women in neurosurgery.

https://thejns.org/doi/abs/10.3171/2020.12.FOCUS20939

KEYWORDS women in neurosurgery; promotion; diversity; gender; meta-analysis; leadership

$\mathrm{T}$ HE underrepresentation of women in academic medicine is a well-documented concern ${ }^{1-3}$ that persists despite concerted efforts to reduce barriers to the entry and promotion of women within the field. ${ }^{4,5}$ While the number of women in medicine has increased dramatically and nearly half of residents across all subspecialties are women, ${ }^{6}$ women remain underrepresented in surgical subspecialties, including neurosurgery. ${ }^{2}$ Recent Associa- tion of American Medical Colleges (AAMC) data report that, of current neurological surgery residents, only $18 \%$ $(n=1479)$ are women, lower than that of otolaryngology $(36 \%)$, plastic surgery $(41 \%)$, vascular surgery $(34 \%)$, and thoracic surgery $(27 \%){ }^{6}$ Regarding faculty composition, while the number of female full professors in surgical departments has increased steadily over the past 20 years, it has increased at a significantly slower rate than female en- 
rollment in surgical training programs. ${ }^{7}$ While the gender representation discrepancy in academic promotion among senior faculty is likely multifactorial, several prior studies have suggested that a gender imbalance in academic publishing could be a significant contributor or indicator. ${ }^{7-10}$ As career advancement in academic medicine is driven substantially by the publication of original research, an underrepresentation of women in early-career publishing would be expected to contribute to underrepresentation of women in academic leadership positions.

"Big data," in the medical context, is a broad term describing the use of large sets of multifaceted clinical data to explore applications beyond the scope of traditional data analysis programs. ${ }^{11}$ Meta-analysis is one form of big data. Big data has been increasingly utilized in neurosurgical work to highlight areas of improvement in clinical arenas and to drive clinical solutions. ${ }^{12,13}$

Small-scale historical analyses have explored the proportion of female authors of original research in other medical and surgical subspecialties ${ }^{14-16}$ including neurosurgery. ${ }^{16}$ However, there exists no large-scale, big data analysis of historical bibliometric data to quantify representation and disparities in the academic publishing gap within the field of neurosurgery.

This work presents the use of an automated prediction model to derive trends in proportion of female first and senior authorship in original research published from 2002 to 2019 in 16 top neurosurgical journals by $h 5$-index. This work also presents an analysis of the likelihood of female first authorship depending on the gender of the senior author using the automated prediction model on a large data set of author names. In addition, the Journal of Neurosurgery is used as a case study to explore the longitudinal presence of female authorship in published articles since the journal's creation in 1944 until 2019.

\section{Methods \\ Data Source}

Analysis included all research published from 2002 to 2019 in the following 16 neurosurgical journals: Acta Neurosurgery, Asian Journal of Neurosurgery, British Journal of Neurosurgery, Journal of Korean Neurosurgical Society, Journal of Neurological Surgery Part B: Skull Base, Journal of Neurosurgery, Journal of Neurosurgery: Pediatrics, Journal of Neurosurgery: Spine, Journal of Neurological Sciences, Neurochirurgie, Neurosurgery, Neurosurgery Clinics, Neurosurgical Focus, Neurosurgical Review, Operative Neurosurgery, Stereotactic and Functional Neurosurgery, Surgical Neurology International, and World Neurosurgery. These journals were selected by their $h 5$-index and represent many of the subfields within neurosurgery. Citation information for publications in these journals was acquired through the MEDLINE and PubMed databases using the Entrez Global Query Search System, given this system robustly covers the published health-related literature. ${ }^{17}$ Two top journals, Journal of Neurological Surgery Part B: Skull Base and Neurochirurgie, were not included in the final analysis due to the use of author initials rather than first names.

As a historical case study, we explored the represen- tation of women in articles published in the Journal of Neurosurgery. Articles published in this journal were obtained from 1944, the journal's inaugural year, to 2019 using volume and issue archives at thejns.org.

Noncitable research items, which were defined as any published items other than journal articles, review articles, case reports, and conference papers, were excluded. Any articles that were attributed to a collective organization rather than a list of individual authors were also excluded.

\section{Gender Inference}

Author gender was predicted from the first name, using a multitiered approach. Each author's given name was compared to the Worldwide Gender-Name Dictionary database associated with 177,043 unique names..$^{18}$ Any names that were not listed and those deemed gender neutral in the Worldwide Gender-Name Dictionary were then referenced against the OpenGenderTracking Project (https:// opengendertracking.github.io/) database, which includes gender information for 101,749 names. Names that were found in neither the Worldwide Gender-Name Dictionary nor the OpenGenderTracking Project and names that were deemed gender-neutral by both databases were referenced against a commercial gender inference service with a database of 2,068,652 names (https://gender-api.com/). The name databases and commercial gender inference service used in the analysis covered a broad set of names from 177 countries. The databases included foreign names and variants of those names rendered in their native scripts, as well as English-language transliterations of those names.

\section{Statistical Analysis}

The year-by-year proportion of female authorship to total authorship was evaluated using a linear regression analysis. Statistical significance was reported using the one-sided t-test generated from the linear regression. When comparing the rate of increase of first and senior authorship, a one-tail hypothesis test was generated by comparing slope coefficients using ANOVA. The correlation between female first authorship likelihood based on female senior authorship was evaluated using a linear regression analysis. Statistical significance was reported using odds ratios from the logistic regression. All statistical analyses were performed with the $\mathrm{R}$ statistical software package (R Foundation for Statistical Computing).

\section{Results \\ Journal Characteristics}

Sixteen of the top 18 major neurosurgery journals by h5-index were included in the study and are listed, along with total numbers of articles from each journal, in Table 1 .

\section{Research Document Characteristics}

A large data set of 68,737 published articles satisfying the above criteria was collected across the 16 journals. After removing duplicates and other invalid articles (e.g., those that were improperly formatted), 66,546 articles remained for analysis. In cases in which there was a sole author, the author was counted both as first and senior 
TABLE 1. Top 18 neurosurgical journals by $h 5$-index

\begin{tabular}{|c|c|c|c|}
\hline & Journal & h5-Index & $\begin{array}{l}\text { No. of } \\
\text { Articles* }\end{array}$ \\
\hline 1 & Journal of Neurosurgery & 64 & 16,018 \\
\hline 2 & Neurosurgery & 55 & 8916 \\
\hline 3 & Journal of Neurosurgery: Spine & 48 & 3644 \\
\hline 4 & World Neurosurgery & 47 & 12,814 \\
\hline 5 & Neurosurgical Focus & 45 & 3222 \\
\hline 6 & Acta Neurochirurgica & 35 & 7303 \\
\hline 7 & Journal of Neurosurgery: Pediatrics & 35 & 2690 \\
\hline 8 & Surgical Neurology International & 27 & 2396 \\
\hline 9 & Operative Neurosurgery & 27 & 1280 \\
\hline 10 & Neurosurgical Review & 27 & 1373 \\
\hline 11 & British Journal of Neurosurgery & 24 & 2874 \\
\hline 12 & Neurosurgery Clinics & 24 & 998 \\
\hline 13 & $\begin{array}{l}\text { Journal of Neurological Surgery Part B: } \\
\text { Skull Base }\end{array}$ & 22 & 0 \\
\hline 14 & Journal of Korean Neurosurgical Society & 22 & 1975 \\
\hline 15 & Stereotactic and Functional Neurosurgery & 21 & 900 \\
\hline 16 & Neurochirurgie $\dagger$ & 16 & 0 \\
\hline 17 & Journal of Neurosurgical Sciences & 16 & 1056 \\
\hline 18 & Asian Journal of Neurosurgery & 15 & 1278 \\
\hline
\end{tabular}

${ }^{*}$ A total of 66,546 articles remained for analysis after removing duplicates and other invalid articles.

† Author initials are used rather than first names in these journals. Therefore, these journals were not included in the final analysis. author. A total of 133,578 first and senior author names were obtained. Gender could not be determined for 5233 names.

\section{Female First and Senior Authorship}

Overall, female first and senior authorships were found in $13.3 \%$ (8826) and 9.1\% (6073) of citable documents, respectively. The proportion of female first authorship increased from $5.8 \%$ of articles in 2002 to $17.2 \%$ in 2019 ( $\mathrm{p}<0.001$, Fig. 1). Female senior authorship increased from $5.5 \%$ in 2002 to $12.0 \%$ in 2019 (p < 0.001, Fig. 1). There was a statistically significant difference between the rates of increase in female first authorship and female senior authorship assuming a linear trend $(\mathrm{p}<0.001$, Fig. 1). Regarding the relationship between the proportion of women in the field versus academic footprint, however, a Wilcoxon signed-rank test demonstrated a significant difference between the year-by-year proportion of neurosurgical trainees who were women $(9.6 \%$ to $17.7 \%$ over 15 years) and the year-by-year proportion of neurosurgical first $(4.8 \%$ to $16.2 \%$ over 17 years $)(p<0.001)$ and senior (4.4\% to $9.6 \%$ over 18 years) $(\mathrm{p}<0.001)$ authors who were women (Fig. 1). With respect to the role of mentorship, an article was more likely to have a female first author if the senior author of the article was female (OR 2.69, CI 2.52-2.86; $\mathrm{p}<0.001$ ).

While most journals exhibited an increasing trend in female first authorship, only 10 journals demonstrated statistically significant increases in the proportion of female first authors over this time period (Table 2 and Fig. 2). In 2019, the Journal of Neurosurgery: Pediatrics had the highest proportion of female first authors $(33.5 \%)$ and Operative Neurosurgery had the lowest proportion of female first authors (12.4\%). Twelve journals had significant

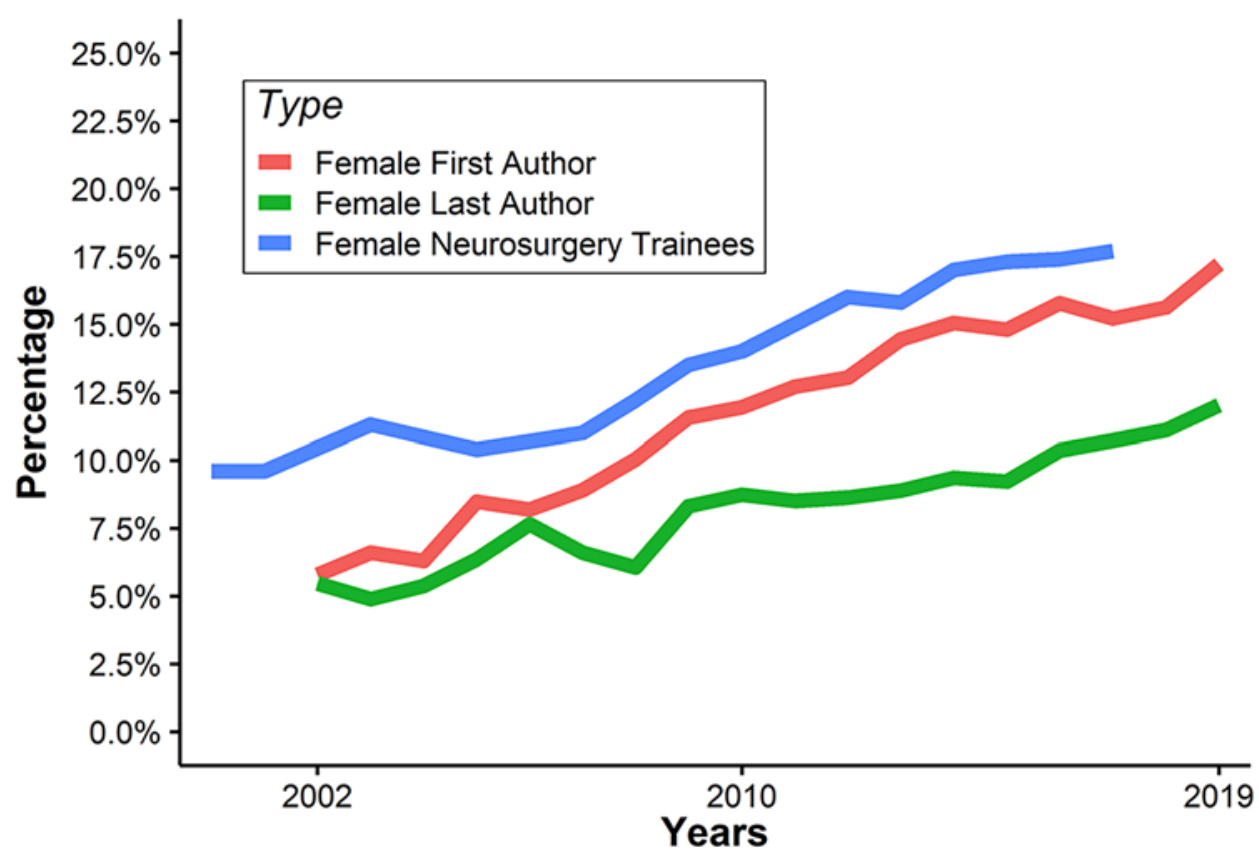

FIG. 1. Trends in female authorship over the study period (2002-2019) for 66,546 articles in 16 major neurosurgical journals. The trend in female neurosurgical trainees over the study period is included for comparison. 
TABLE 2. Percentage of female first and senior authors in the first and final years for which data were available for each of the 16 included journals

\begin{tabular}{lcccccc}
\hline \multicolumn{1}{c}{ Journal } & $\begin{array}{c}\text { 1st Author } \\
\text { Year 1* }\end{array}$ & $\begin{array}{c}\text { 1st Author } \\
\text { Final Year }\end{array}$ & p Value & $\begin{array}{c}\text { Senior Author } \\
\text { Year 1* }\end{array}$ & $\begin{array}{c}\text { Senior Author } \\
\text { Final Year }\end{array}$ & p Value \\
\hline Acta Neurochirurgica & $5.0 \%(2008)$ & $16.7 \%$ & 0.001 & $2.1 \%(2008)$ & $9.6 \%$ & 0.18 \\
\hline Asian Journal of Neurosurgery & $12.0 \%(2010)$ & $14.9 \%$ & 0.26 & $11.1 \%(2010)$ & $23.8 \%$ & 0.003 \\
\hline British Journal of Neurosurgery & $1.9 \%(2008)$ & $14.4 \%$ & 0.15 & $1.9 \%(2008)$ & $11.4 \%$ & 0.007 \\
\hline Journal of Korean Neurosurgical Society & $8.2 \%(2007)$ & $15.7 \%$ & 0.07 & $6.1 \%(2007)$ & $15.7 \%$ & $<0.001$ \\
\hline Journal of Neurosurgery & $8.7 \%(2002)$ & $21.3 \%$ & $<0.001$ & $7.8 \%(2002)$ & $13.3 \%$ & 0.0001 \\
\hline Journal of Neurosurgery: Pediatrics & $17.0 \%(2008)$ & $33.5 \%$ & 0.002 & $7.1 \%(2008)$ & $19.1 \%$ & 0.0002 \\
\hline Journal of Neurosurgery: Spine & $3.9 \%(2004)$ & $15.3 \%$ & $<0.001$ & $0 \%(2004)$ & $9.9 \%$ & 0.02 \\
\hline Journal of Neurosurgical Sciences & $15.8 \%(2016)$ & $17.0 \%$ & 0.38 & $10.5 \%(2016)$ & $8.8 \%$ & 0.03 \\
\hline Neurosurgery & $6.7 \%(2002)$ & $19.0 \%$ & $<0.001$ & $7.2 \%(2002)$ & $13.1 \%$ & 0.01 \\
\hline Neurosurgery Clinics & $19.1 \%(2002)$ & $18.2 \%$ & 0.26 & $7.1 \%(2002)$ & $10.9 \%$ & 0.33 \\
\hline Neurosurgical Focus & $6.6 \%(2002)$ & $23.5 \%$ & 0.002 & $8.5 \%(2002)$ & $7.8 \%$ & 0.34 \\
\hline Neurosurgical Review & $6.6 \%(2002)$ & $17.8 \%$ & $<0.001$ & $6.1 \%(2002)$ & $7.5 \%$ & 0.01 \\
\hline Operative Neurosurgery & $5.6 \%(2015)$ & $12.4 \%$ & 0.31 & $5.6 \%(2015)$ & $4.8 \%$ & 0.46 \\
\hline Stereotactic and Functional Neurosurgery & $2.3 \%(2002)$ & $22.4 \%$ & 0.004 & $4.7 \%(2002)$ & $12.2 \%$ & 0.01 \\
\hline Surgical Neurology International & $11.0 \%(2010)$ & $17.4 \%$ & 0.03 & $12.1 \%(2010)$ & $19.5 \%$ & 0.007 \\
\hline World Neurosurgery & $6.8 \%(2010)$ & $15.2 \%$ & $<0.001$ & $6.8 \%(2010)$ & $11.8 \%$ & $<0.001$ \\
\hline Total & $4.8 \%$ & $16.2 \%$ & $<0.001$ & $4.4 \%$ & $9.6 \%$ & $<0.001$ \\
\hline Nhe & & & & & \\
\hline
\end{tabular}

* The years in parentheses represent the first year that data were available for each journal.

increases in the proportion of female senior authors. In 2019, Asian Journal of Neurosurgery had the highest proportion of female senior authors (23.8\%) and Operative Neurosurgery had the lowest proportion of female senior authors (4.8\%).

\section{Trends in Journal of Neurosurgery: A Case Study}

To delve into the details of authorship trends over a longer period of time, we selected one journal, the Journal of Neurosurgery, and tracked changes in female first and senior authorship. We found that, between 1944 and 2019, female first authorship increased from $0 \%$ to $18.6 \%$ and female senior authorship increased from $4.7 \%$ to $11.7 \%$ (Fig. 3). A divergence of growth rates between female first and senior authors occurred in 1994. Prior to 1994, there were indistinguishable growth rates between female first and senior authorship $(\mathrm{p}=0.29)$; after 1994, female first and senior author growth rates are significantly different $(p=0.04)$. The rate of increase in female first authorship before and after 1994 was significantly different $(\mathrm{p}<0.001)$, although this was not true for female senior authorship $(\mathrm{p}=0.24)$.

\section{Discussion}

\section{Summary}

In this analysis, we utilize methods in meta-analysis to assess the representation of women in neurosurgical literature. Overall, the proportion of female first and senior authors in neurosurgery has increased significantly, as observed between 2002 and 2019. These increases were also found for the majority of individual journals investigated. We found the highest proportion of women as first authors in Journal of Neurosurgery: Pediatrics, as well as significant increases in both female first and senior authors. This is consistent with previous findings that women make up a higher proportion of pediatric neurosurgeons than nonpediatric neurosurgeons. ${ }^{19}$ The only spine subspecialty journal included, Journal of Neurosurgery: Spine, ranked among the lowest for female representation as first and senior authors, at fifth and seventh from last, respectively. This is also consistent with previous findings within clinical practice, with lower female representation in spine surgery. ${ }^{8}$ The sole stereotactic/functional subspecialty journal, Stereotactic and Functional Neurosurgery, by contrast, ranked among the journals with the highest proportion of female first authors (third) and senior authors (seventh) (Fig. 2). The contrast between these three subspecialties (pediatrics, spine, and stereotactic/functional) indicates that the overall increase in female representation seen in the cohort is not distributed equally among the neurosurgical subspecialties. Operative Neurosurgery, which had the smallest proportion of both female first and senior authors, was relatively lacking in publications with female lead authorship. This possibly highlights bias that female neurosurgeons face in the operative or technical arenas of neurosurgery or inadequate mentorship to produce higher caliber publications.

Despite the overall increase in female authorship over time, the rate of increase in female first authors was significantly greater than that of female senior authors, indicating a relative stagnation in more junior faculty positions. Additionally, female first authors in neurosurgery were more likely to publish an article when the senior author was female, pointing to the significance of mentorship. In the historical analysis of the Journal of Neurosurgery, we show 


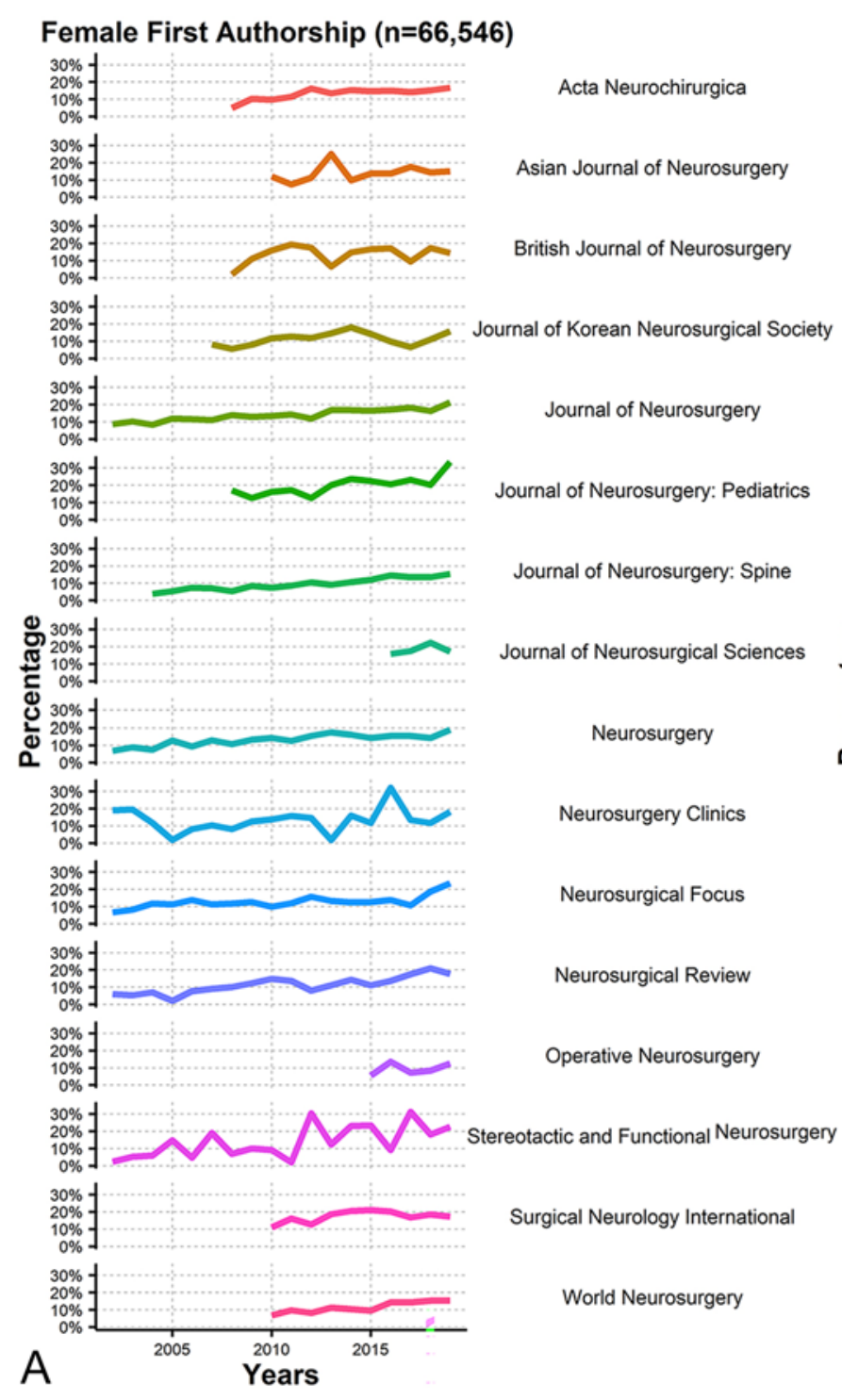

Female Senior Authorship $(n=66,546)$
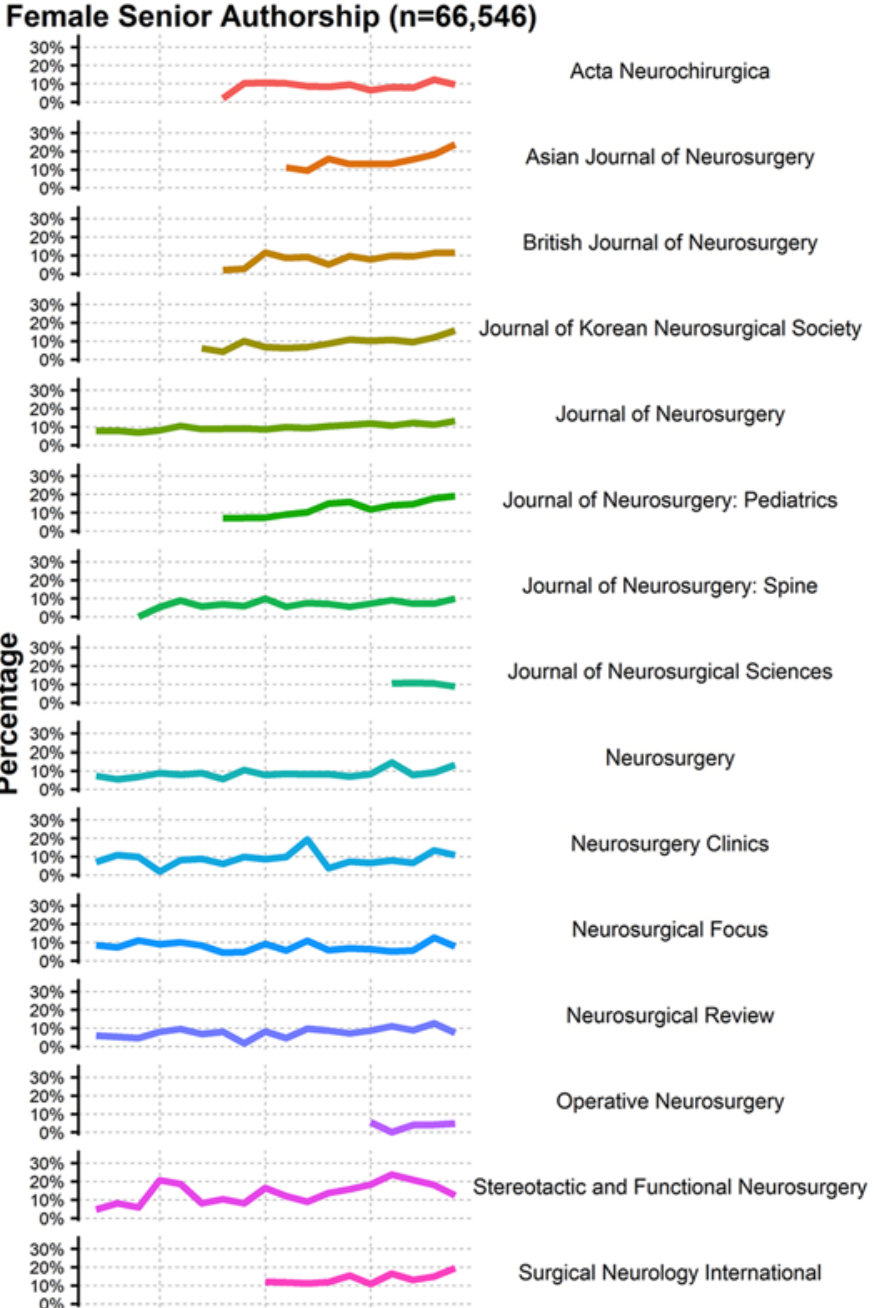

World Neurosurgery

FIG. 2. Trends in female first authorship (A) and female senior authorship (B) by journal. A total of 66,546 articles were included.

a steady year-by-year increase in female first and senior authorship early on, with significant divergence among the two beginning during the 1990s despite a steady increase in the presence of women in the field. These trends in the rise in female authorship over time and the increase in female first authorship if the senior author was female parallel other studies related to gender disparities in female authorship in neurosurgery. ${ }^{20}$ While this continued increase in academic presence is encouraging, the proportional representation in neurosurgical-specific literature is not commensurate with the proportion of female neurosurgical trainees and, therefore, women in the workforce. This disparity highlights a source of necessary improvement in identifying continued barriers to career advancement in neurosurgery, with particular focus on subdisciplines with the greatest degree of female underrepresentation. The applicability of the meta-analysis modality is vast, as the multimodal and multilevel nature of big data has been used to study minority health disparities ${ }^{21}$ and to implement and deliver global neurosurgical care. ${ }^{22}$

\section{Implications of Findings}

While the overall increase in both female neurosurgical first authors and senior authors is encouraging, the numbers trail substantially behind those of their male colleagues. This is particularly discouraging when comparing the disproportionate rate of increase of female senior authors in comparison to female first authors and female trainees. While it is possible that some of this effect is due to a time-delay bias (as senior authorship requires career progression and thus time), it must also be considered as an indication that mid- to late-career female neurosurgeons are not advancing in their careers as predicted or as steadily as their male colleagues. This is corroborated by the divergence of increase between first and senior female first authors in our case study of the Journal of Neurosurgery. 


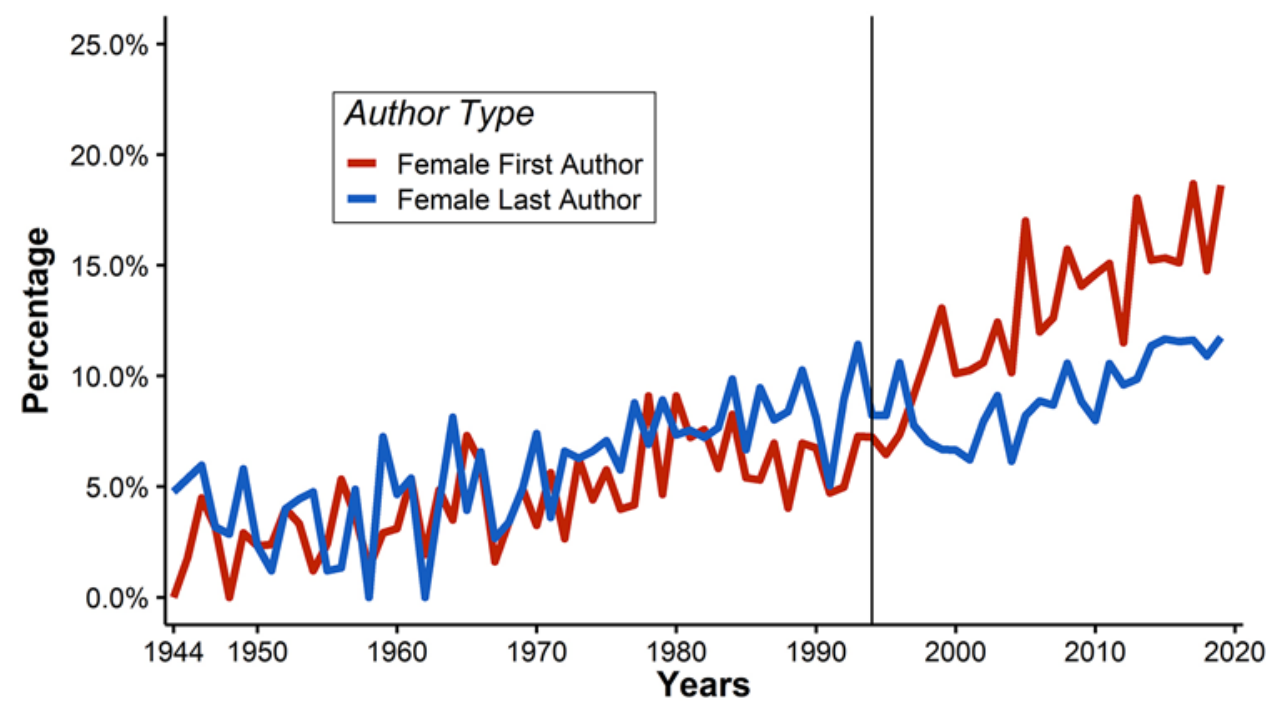

FIG. 3. Case study. Comparison of trends in female first authorship and female senior authorship in 21,346 articles in the Journal of Neurosurgery between 1944 and 2019. The growth rate between first and senior authorship diverged after 1994, with the growth rate of first authorship greater than the growth rate of senior authorship $(p=0.04)$.

This is mirrored in the gender composition of the field. While women are increasingly represented in assistant and associate professorship positions $(15 \%$ and $13 \%$, respectively), women are underrepresented in full professorship positions $(5.8 \%){ }^{23}$

Finally, our finding that articles with female first authors were more likely to have a female senior author has interesting implications for mentorship in the field. This argues for the increased need for senior female mentorship. A similar phenomenon has also been described in other fields, such as anesthesiology, ${ }^{24}$ and in previous studies of neurosurgical authorship. ${ }^{20}$ In academic surgery, the limited number of senior female mentors has been described by others as one relational barrier to academic progress for women in neurosurgery. ${ }^{25}$

A 2008 study commissioned by the American Association of Neurological Surgeon $\mathbf{s}^{15}$ found that the percentage of female trainees in neurosurgery had increased over the prior decades, but it found no corresponding increase in the representation of women in neurosurgical leadership. Based on these findings, the authors recommended that the field of neurosurgery increase female resident and faculty enrollment to $20 \%$ by 2012 , while simultaneously raising the number of required gender diversity programs.$^{15}$ While this strategy has successfully increased female presence in the field, this presence has not translated to increased representation in leadership and senior academic roles reflective of successful career advancement. As a result, the presence of mentorship for women aiming to advance within academic neurosurgery remains limited despite the increased overall presence of women in the neurosurgical workforce. There are additional components involved in fostering and strategically organizing career advancement beyond increased presence. Identification of barriers or lack of facilitators for this process of advancement following increased recruitment is essential in understanding and addressing continued disparities.
Because career advancement in academic medicine is primarily driven by original research, we hypothesized that the apparent gender gap in neurosurgical publishing might point to the downstream effect of such obstacles, highlighting areas of greatest impact in improvement. Evidence outside of neurosurgery supports this idea. ${ }^{26}$ Data on major early career development awards, much of which are determined by publication history and impact, reveal that women are less likely to be granted these awards than men. ${ }^{4,5}$ Notably, even when women are able to reach these academic leadership positions, there is still a disparity in publication productivity. ${ }^{23}$ Furthermore, despite the fact that women had increased fellowship completion over their male counterparts, women still had lower scholarly productivity. ${ }^{27}$ Mentorship, as described in this study, is to be distinguished from sponsorship. Sponsorship is the use of one's own advanced status to advocate for the advancements and opportunities for the mentee. ${ }^{28}$ While many women cite the lack of mentorship as a significant factor in career advancement, sponsorship provides concrete opportunities for career progress.

Bias can also play a role in the ability to achieve publication. In general, studies have shown that women are persistently underrepresented in surgical editorial boards, although their numbers in the field are rising..$^{29-31} \mathrm{~A}$ recent study of high-impact general surgery journals showed that over the past 20 years, the composition of female members of editorial boards has risen from 5\% to $19 \%{ }^{29}$ Currently, in some of the high-impact neurosurgical journals, the composition of the editorial boards are as follows. Neurosurgical Focus has 1 editor-in-chief and 2 associate editors ( $0 / 3$ are women); however, the editorial board is variable with the monthly topics, and so the ratio varies from month to month, for each issue, from 0 of 5 to 5 of 5 being women. The Journal of Neurosurgery has 22 members on the editorial board, with 6 members being women. Neurosurgery has 7 editorial board members, with 4 members be- 
ing women. The Journal of Neurosurgery: Pediatrics had 16 members on the editorial board, with 2 members being women. Notably, in these journals, none of the editors-inchief are women. There are limited data on whether the data review process is anonymized. Further research is required to specifically delineate the forward progression of these boards, and the impact of these board compositions on the likelihood of women faculty publishing in the field.

\section{Limitations}

This study is limited by the accuracy of our gender review methodology; therefore, these described limitations include those inherent to the use of meta-analysis itself. For example, our predictive workflow yielded binary gender outcomes (male/female), thus treating cases with low certainty identically to those with very high certainty. Additionally, it has no means of accounting for individuals of one gender with names that are conventionally given to the other gender. It fails to incorporate any individuals that are gender nonbinary or gender nonconforming. ${ }^{32}$ In light of this, however, our final gender inference prediction rate was found to be similar to those of prior studies. ${ }^{8}$ The study is also limited by the number of neurosurgery journals included in this analysis, thus potentially limiting the scope or generalizability of our results. Furthermore, only 7 of the 16 journals analyzed in this study had data in 2002, with some journals first publishing as late as 2016. Similarly, this study does not include neurosurgical articles that were published in nonneurosurgical journals. While we recognize this as a potential limitation, we believe that extension to include articles in these journals would be infeasible due to varied or absent subject grouping (e.g., MeSH term) in many journals. Finally, due to the collaborative nature of the field of neurosurgery, it is possible that some authors included here are not neurosurgeons; it is likely that some percentage of neurologists, radiation oncologists, orthopedic surgeons, or any number of other collaborator roles were inadvertently included in our author list.

\section{Conclusions}

Using metadata techniques, we found an increase in female neurosurgical first and senior authorship, with the growth of female senior authorship lagging behind the growth in female first authorship. Overall, senior authorship continues to lag significantly behind overall female representation in the field and mirrors the parallel disparity in promotion and career advancement of women in neurosurgery. Thus, while we believe that there is further improvement to be made, this study serves as an indicator that the field of neurosurgery continues to improve in its gender diversity. We, as neurosurgeons, need to continue to mentor our entire workforce toward career advancement to support innovation and advancement of the field as a whole through the inclusion of varied perspectives, talents, and contributions. As a result, we can provide a more balanced, and therefore powerful, voice for the future of neurosurgery.

\section{References}

1. Rochon PA, Davidoff F, Levinson W. Women in academic medicine leadership: has anything changed in 25 years? Acad Med. 2016;91(8):1053-1056.

2. Bickel J, Wara D, Atkinson BF, et al. Increasing women's leadership in academic medicine: report of the AAMC Project Implementation Committee. Acad Med. 2002;77(10): 1043-1061.

3. Abelson JS, Chartrand G, Moo TA, et al. The climb to break the glass ceiling in surgery: trends in women progressing from medical school to surgical training and academic leadership from 1994 to 2015. Am J Surg. 2016;212(4):566-572.e1.

4. Jagsi R, Motomura AR, Griffith KA, et al. Sex differences in attainment of independent funding by career development awardees. Ann Intern Med. 2009;151(11):804-811.

5. Ley TJ, Hamilton BH. Sociology. The gender gap in NIH grant applications. Science. 2008;322(5907):1472-1474.

6. Association of American Medical Colleges. 2018-2019 The state of women in academic medicine: exploring pathways to equity. Accessed January 13, 2021. https://www.aamc. org/data-reports/data/2018-2019-state-women-academicmedicine-exploring-pathways-equity

7. Mueller C, Wright R, Girod S. The publication gender gap in US academic surgery. BMC Surg. 2017;17(1):16.

8. Sing DC, Jain D, Ouyang D. Gender trends in authorship of spine-related academic literature-a 39-year perspective. Spine J. 2017;17(11):1749-1754.

9. Bergeron JL, Wilken R, Miller ME, et al. Measurable progress in female authorship in otolaryngology. Otolaryngol Head Neck Surg. 2012;147(1):40-43.

10. Long MT, Leszczynski A, Thompson KD, et al. Female authorship in major academic gastroenterology journals: a look over 20 years. Gastrointest Endosc. 2015;81(6):1440-1447.e3.

11. Cobb AN, Benjamin AJ, Huang ES, Kuo PC. Big data: more than big data sets. Surgery. 2018;164(4):640-642.

12. Panesar SS, Fernandez-Miranda J. Big data, big impact: the potential for data science in neurosurgery. World Neurosurg. 2020;138:558-559.

13. Oravec CS, Motiwala M, Reed K, et al. Big data research in neurosurgery: a critical look at this popular new study design. Neurosurgery. 2018;82(5):728-746.

14. Fishman M, Williams WA II, Goodman DM, Ross LF. Gender differences in the authorship of original research in pediatric journals, 2001-2016. J Pediatr. 2017;191:244-249.e1.

15. Benzil DL, Abosch A, Germano I, et al. The future of neurosurgery: a white paper on the recruitment and retention of women in neurosurgery. J Neurosurg. 2008;109(3):378-386.

16. Aslan A, Kuzucu P, Karaaslan B, Börcek AÖ. Women in neurosurgery: gender differences in authorship in high-impact neurosurgery journals through the last two decades. World Neurosurg. 2020;138:374-380.

17. Entrez Programming Utilities (E-Utilities). Encyclopedia of Genetics, Genomics, Proteomics and Informatics. Springer; 2008.

18. Raffo J. Worldwide Gender-Name Dictionary. WIPO Economics \& Statistics Related Resources 10. World Intellectual Property Organization-Economics and Statistics Division; 2016.

19. Durham SR, Lane JR, Shipman SA. The pediatric neurosurgical workforce: defining the current supply. Clinical article. J Neurosurg Pediatr. 2009;3(1):1-10.

20. Farhan SA, Shahid I, Siddiqi J, Khosa F. Assessing the gap in female authorship in neurosurgery literature: a 20-year analysis of sex trends in authorship. World Neurosurg. 2020;141: e661-e669.

21. Zhang X, Pérez-Stable EJ, Bourne PE, et al. Big data science: opportunities and challenges to address minority health and health disparities in the 21st century. Ethn Dis. 2017;27(2): 95-106.

22. West JL, Fargen KM, Hsu W, et al. A review of Big Data analytics and potential for implementation in the delivery of global neurosurgery. Neurosurg Focus. 2018;45(4):E16. 
23. Odell T, Toor H, Takayanagi A, et al. Gender disparity in academic neurosurgery. Cureus. 2019;11(5):e4628.

24. Miller J, Chuba E, Deiner S, et al. Trends in authorship in anesthesiology journals. Anesth Analg. 2019;129(1):306-310.

25. Thompson-Burdine JA, Telem DA, Waljee JF, et al. Defining barriers and facilitators to advancement for women in academic surgery. JAMA Netw Open. 2019;2(8):e1910228.

26. Marrone AF, Berman L, Brandt ML, Rothstein DH. Does academic authorship reflect gender bias in pediatric surgery? An analysis of the Journal of Pediatric Surgery, 2007-2017. J Pediatr Surg. 2020;55(10):2071-2074.

27. Behmer Hansen RT, Silva NA, Cuevas R, et al. Fellowship, gender, and scholarly productivity: trends among academic neurosurgeons in the US. J Neurosurg. Published online August 28, 2020. doi:10.3171/2020.5.JNS20577

28. Stephens EH, Heisler CA, Temkin SM, Miller P. The current status of women in surgery: how to affect the future. JAMA Surg. 2020;155(9):876-885.

29. Harris CA, Banerjee T, Cramer M, et al. Editorial (spring) board? Gender composition in high-impact general surgery journals over 20 years. Ann Surg. 2019;269(3):582-588.

30. Chen K, Ha G, Schultz BD, et al. Is there gender inequality in plastic surgery? Evaluation of society leadership and composition of editorial boards. Plast Reconstr Surg. 2020;145(2): 433e-437e.

31. Amrein K, Langmann A, Fahrleitner-Pammer A, et al. Women underrepresented on editorial boards of 60 major medical journals. Gend Med. 2011;8(6):378-387.

32. Frohard-Dourlent H, Dobson S, Clark BA, et al. "I would have preferred more options": accounting for non-binary youth in health research. Nurs Inq. 2017;24(1):e12150.

\section{Disclosures}

The authors report no conflict of interest concerning the materials or methods used in this study or the findings specified in this paper.

\section{Author Contributions}

Conception and design: Hoffman, Taha, Sadda, Londono, Greenfield, Pannullo. Acquisition of data: Taha, Sadda, Winston, Londono. Analysis and interpretation of data: Taha, Sadda, Winston, Londono. Drafting the article: Taha, Sadda, Winston, Odigie, Londono. Critically revising the article: Hoffman, Taha, Winston, Odigie, Londono, Greenfield, Pannullo. Reviewed submitted version of manuscript: all authors. Approved the final version of the manuscript on behalf of all authors: Hoffman. Statistical analysis: Taha, Sadda. Administrative/technical/ material support: Greenfield, Pannullo. Study supervision: Hoffman, Greenfield, Pannullo.

\section{Supplemental Information \\ Videos}

Video Abstract. https://vimeo.com/509834017.

\section{Correspondence}

Caitlin Hoffman: NewYork-Presbyterian Hospital, Weill Cornell Medical College, New York, NY.ceh2003@med.cornell.edu. 